\title{
Effect of gastric secretory inhibitors on the gastric mucosal barrier
}

\author{
P. E. O'BRIEN AND D. C. CARTER \\ From the University Department of Clinical Surgery, Royal Infirmary, Edinburgh
}

SUMMARY The effects of the synthetic prostaglandin 16,16 dimethyl- $E_{2}$ methyl ester (16-diMe$\mathrm{PGE}_{2}$ ) and the histamine $\mathrm{H}_{2}$-receptor antagonist metiamide on the gastric mucosal barrier have been studied using the Heidenhain pouch dog model. The 16-diMe-PGE $\mathrm{P}_{2}$ caused significant change in the ionic permeability of the mucosa when instilled into the pouch in a concentration of $300 \mu \mathrm{g} / 20 \mathrm{ml}$. Intravenous administration of $16-\mathrm{diMe}^{-} \mathrm{PGE}_{2}$ did not alter the barrier nor did it alter the response of the mucosa to sodium taurocholate. Metiamide given into the pouch did not affect the mucosal barrier and the response to taurocholate was not affected when metiamide was given locally or intravenously.

Prostaglandin $E_{2}$ and several of its analogues and the histamine $\mathrm{H}_{2}$-receptor antagonists have recently been shown to be potent inhibitors of basal and stimulated gastric acid secretion (Wada and Ishizawa, 1970; Karim, Carter, Bhana, and Ganesan, 1973; Grossman and Konturek, 1974; Carter, Forrest, Werner, Heading, Park, and Shearman, 1974), and these drugs are currently being evaluated in patients with peptic ulcer.

The following experiments were carried out to determine the effect of the synthetic prostaglandin 16,16 dimethyl- $E_{2}$ methyl ester (16-diMe-PGE ${ }_{2}$ ) and the histamine $\mathrm{H}_{2}$-receptor antagonist metiamide on the ionic permeability of the gastric mucosa with two questions in mind: (1) Do they alter the gastric mucosal barrier? (2) Can they modify the effect of a known 'barrier breaker'?

\section{Methods}

Three male dogs of approximately $15 \mathrm{~kg}$ in weight were used. Each was prepared with an antrectomy and a vagally denervated fundic pouch drained by a Gregory cannula. This pouch did not secrete acid in the basal state. No experiments were done during the first postoperative month. The animals were deprived of food but not water for 18 hours before each experiment and were trained to stand quietly partially supported in slings.

Each experiment consisted of six 30-minute

Received for publication 12 March 1975 periods. At the start of each period $25 \mathrm{ml}$ of solution was instilled into the pouch via a short length of wide-bore polyethylene tubing passed through a rubber seal of the Gregory cannula. The fluid was then mixed thoroughly with the residual pouch fluid by repeated aspiration and reinstillation using a 30-ml syringe. A 5-ml initial sample was then withdrawn. The fluid then remained in the pouch for 30 minutes, after which time it was mixed thoroughly with the syringe and a final $5-\mathrm{ml}$ sample taken. The remaining fluid was discarded, the pouch rinsed with basal solution and the next period commenced. It is difficult to empty the pouch completely before the commencement of each period and small amounts of fluid may remain in the potential dead space of the tubing leading into the cannula. Every attempt was made to ensure complete emptying but to minimize this source of error, a volume marker was added to the instillate and correction made for volume changes.

Periods 1 and 2 were used as control periods during which basal solution was instilled. The basal solution consisted of 80 m-equiv/1 of $\mathrm{HCl}$ made isotonic with $\mathrm{NaCl}$. Polyethylene glycol labelled with ${ }^{14} \mathrm{C}$ (New England Nuclear) was added to act as a volume marker and $1 \mathrm{~g}$ of unlabelled polyethylene glycol (BDH) was also used to minimize loss of the labelled compound from surface adherence within the pouch.

Period 3 was the test period during which the instilled solution was either the basal solution or a taurocholate solution in which $20 \mathrm{mM}$ sodium taurocholate (Koch-Light) replaced equivalent 

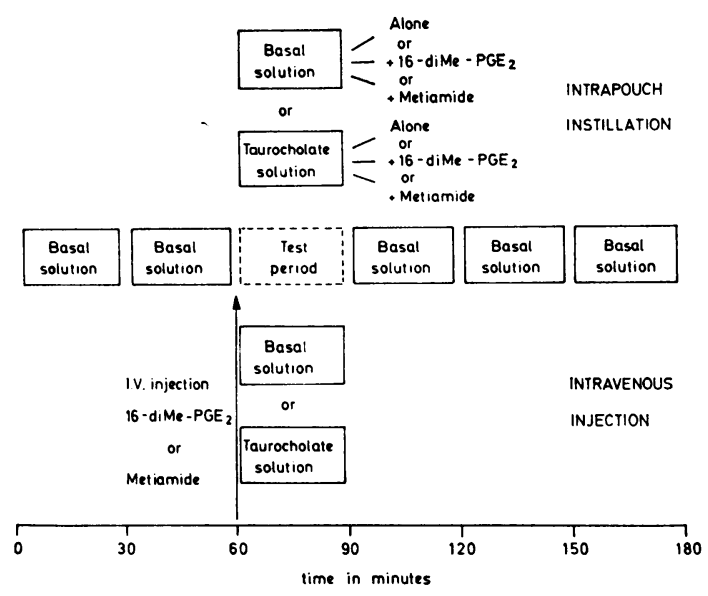

Fig. 1 Experimental plan showing the different types of solution used in the test period. The upper part of the figure shows the solution used in association with instillation of $P G$ or metiamide into the pouch. The lower part refers to the administration of $P G$ or metiamide by bolus intravenous injection.

amounts of $\mathrm{NaCl}$, the basal and taurocholate solutions being identical in all other respects (fig 1). In experiments studying the effects of 16-diMe-PGE 2 or metiamide in the pouch, these agents were added to the test solution immediately before the start of the third period. The doses used were 16-diMe-PGE $2,300 \mu \mathrm{g}$ in $20 \mathrm{ml}$ of the basal or taurocholate solution, and metiamide, $220 \mathrm{mg}$ in $20 \mathrm{ml}$ of basal or taurocholate solution. When these compounds were given by intravenous injection, $7.5 \mu \mathrm{g}$ or $30 \mu \mathrm{g}$ of $16-\mathrm{diMe}^{-\mathrm{PGE}_{2}}$ and $75 \mathrm{mg}$ of metiamide were given as statum injections immediately before the start of period 3 . The prostaglandin was initially dissolved in absolute alcohol $(2 \mathrm{mg} / \mathrm{ml})$. Both agents were diluted to $10 \mathrm{ml}$ with saline before intravenous injection.

During periods 4,5 , and 6 the basal solution was instilled.

The initial and final samples of each period plus a sample of the basal and test solutions were then assayed for $\mathrm{H}^{+}$concentration by titration to $\mathrm{pH} \mathrm{7.0}$ with $0 \cdot 1 \mathrm{~N} \mathrm{NaOH}$ using an automatic titrator (Radiometer). An aliquot of the derived neutral solution was then added to a liquid scintillator (NE 260 Nuclear Chicago). The initial and final sample of each period were assayed for $\mathrm{Na}^{+}$concentration by a flame photometer (EEL 150). The change in volume during each period was calculated by using the change in ${ }^{14} \mathrm{C}$ activity according to the formula: Final volume $=\frac{\text { initial volume } \times \text { initial }{ }^{14} \mathrm{C} \text { activity }}{\text { final }{ }^{14} \mathrm{C} \text { activity }}$.
The difference between the initial and final amounts of $\mathrm{H}^{+}$and $\mathrm{Na}^{+}$for each period was then calculated as ion flux $=$ (final ion concentration $\times$ final volume) - (initial ion concentration $x$ initial volume). The mean and SEM for the change in mass of $\mathrm{H}^{+}$and $\mathrm{Na}^{+}$for each series of six experiments (two experiments in each of three dogs) was calculated and the significance of differences determined by Students' $t$ test.

\section{Results}

\section{CONTROL EXPERIMENTS}

The changes in back diffusion of $\mathrm{H}^{+}$and $\mathrm{Na}^{+}$ output when the pouch is perfused for the six periods with basal solution (fig 2) demonstrate that a low and stable ionic flux occurs in the basal state. With the addition of taurocholate solution during

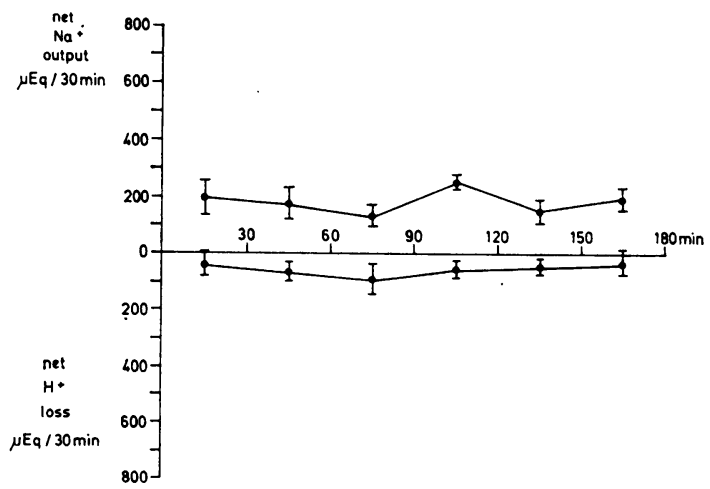

Fig. 2 Basal net $\mathrm{Na}^{+}$output and net $\mathrm{H}^{+}$loss. In this and subsequent figures each point represents the mean with SEM of six values obtained from two experiments in each of the three dogs.

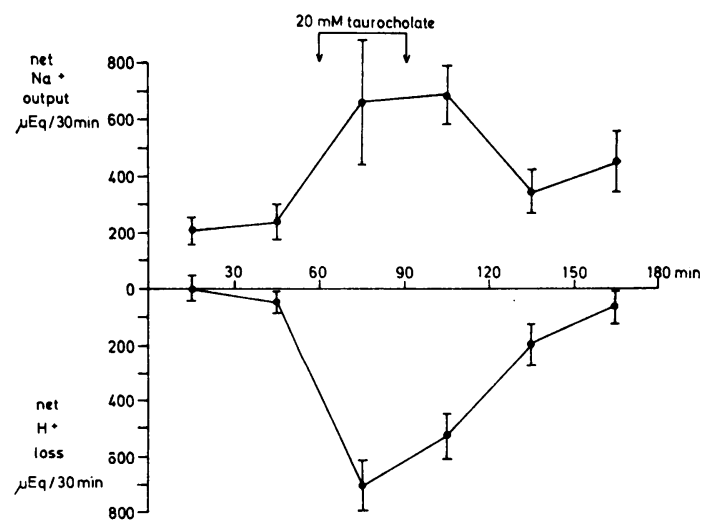

Fig. 3 Changes in net $\mathrm{Na}^{+}$output and net $\mathrm{H}^{+}$loss after exposure to $20 \mathrm{mM}$ taurocholate during period 3. 


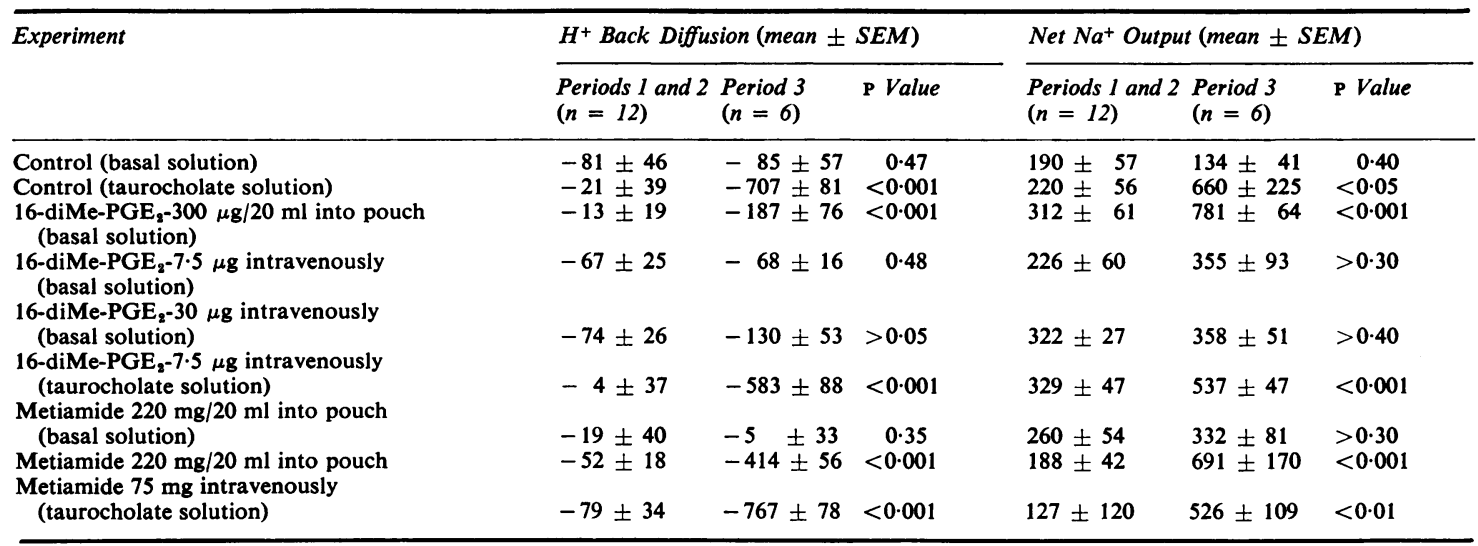

Table I Comparison of ionic fluxes between control and test periods

period 3 (fig 3, table I) a marked and highly significant increase in both $\mathrm{H}^{+}$back duffusion and $\mathrm{Na}^{+}$ output is evident. A return to the control situation occurs during the final two periods.

EFFECT OF 16, 16 DIMETHYL-E 2 METHYL ESTER

\section{Local instillation}

Administration of the prostaglandin analogue to the pouch resulted in a marked increase in the rate of net $\mathrm{Na}^{+}$output and a moderate increase in the rate of $\mathrm{H}^{+}$back diffusion from the pouch (fig 4). Both of these changes are highly significant $(P<0.001$, table I) and persist through the next period. When compared to the control taurocholate experiments this increase in $\mathrm{Na}^{+}$output is of the same order of magnitude as was achieved with $20 \mathrm{mM}$ taurocholate.

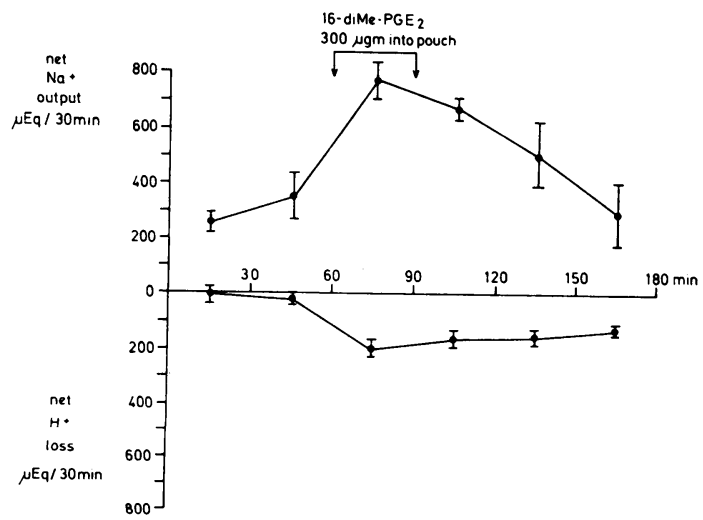

Fig. 4 Changes in net $\mathrm{Na}^{+}$output and net $\mathrm{H}^{+}$loss after addition of 16-diMe-PGE $(300 \mu \mathrm{g} / 20 \mathrm{ml})$ to the pouch during period 3.
The rate of $\mathrm{H}^{+}$back diffusion is, however, significantly less marked. Bleeding from the pouch after administration of 16-diMe-PGE 2 occurred in four of the six experiments. In one dog the minor bleeding persisted for two days after completion of the experiment, and six periods of pouch perfusion with the basal solution performed at 48 hours after exposure to prostaglandins in this animal showed an $\mathrm{H}^{+}$back diffusion of $127 \pm 1 \mu$-equiv/30 min and a net $\mathrm{Na}^{+}$output of $794 \pm 84 \mu$-equiv/30 min (mean and SEM, $\mathrm{n}=6$ ). The control values for this dog were $112 \pm 29$ and $226 \pm 28$ respectively $(\mathrm{n}=12)$. Thus a highly significant increase in $\mathrm{Na}^{+}$ output persisted $(P<0.001)$ for at least 48 hours after exposure to 16 -diMe-PGE 2 in this animal.

\section{Intravenous}

The administration of $7.5 \mu \mathrm{g}$ of $16-\mathrm{diMe}^{-\mathrm{PGE}_{2}}$ intravenously (fig 5, table I) did not result in any

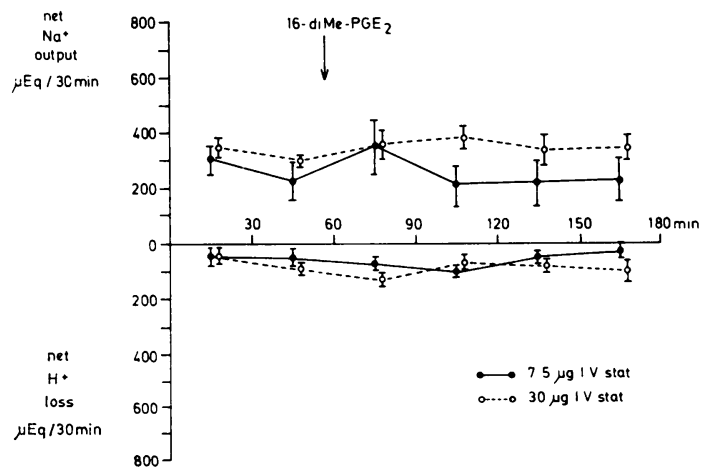

Fig. 5 Changes in net $\mathrm{Na}^{+}$output and net $\mathrm{H}^{+}$loss after administration of 16-diMe-PGE $E_{2}$ intravenously in doses of $7.5 \mu \mathrm{g}$ and $30 \mu \mathrm{g}$. 
significant change in the $\mathrm{H}^{+}$and $\mathrm{Na}^{+}$fluxes. In view of the marked effect of the drug when administered locally the dose was increased fourfold to $30 \mu \mathrm{g}$ but still did not alter the ionic fluxes (table I). No bleeding occurred into the pouch following intravenous injection of prostaglandin. Mild transient vomitting was a common feature after 16diMe-PGE 2 regardless of the route of administration.

When 7.5 $\mu \mathrm{g}$ 16-diMe-PGE 2 was administered intravenously before the mucosa was exposed to the taurocholate solution (fig 6 , table I) the changes in ionic permeability were not significantly different from those achieved with taurocholate alone.

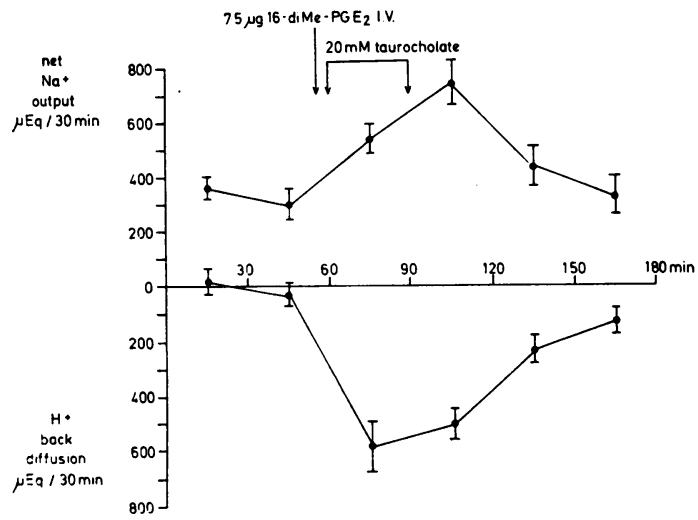

Fig. 6 Changes in net $\mathrm{Na}^{+}$output and net $\mathrm{H}^{+}$loss after intravenous injection of 7.5 $\mu \mathrm{g} \mathrm{16-diMe-PGE_{2 }}$ before period 3 and instillation of taurocholate solution during the period.

\section{EFFECT OF METIAMIDE}

When $220 \mathrm{mg}$ metiamide was added to the pouch in $20 \mathrm{ml}$ of basal solution (fig 7) the $\mathrm{H}^{+}$and $\mathrm{Na}^{+}$

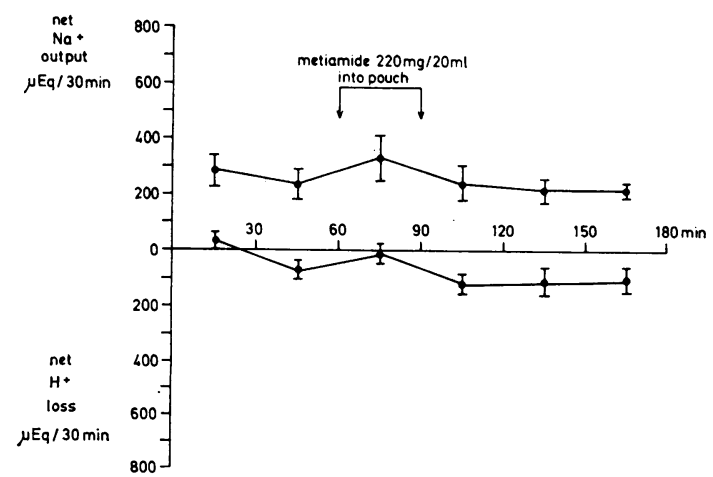

Fig. 7 Changes in the net $\mathrm{Na}^{+}$output and net $\mathrm{H}^{+}$loss after addition of $220 \mathrm{mg}$ of metimide to $20 \mathrm{ml}$ of basal solution during period 3 .

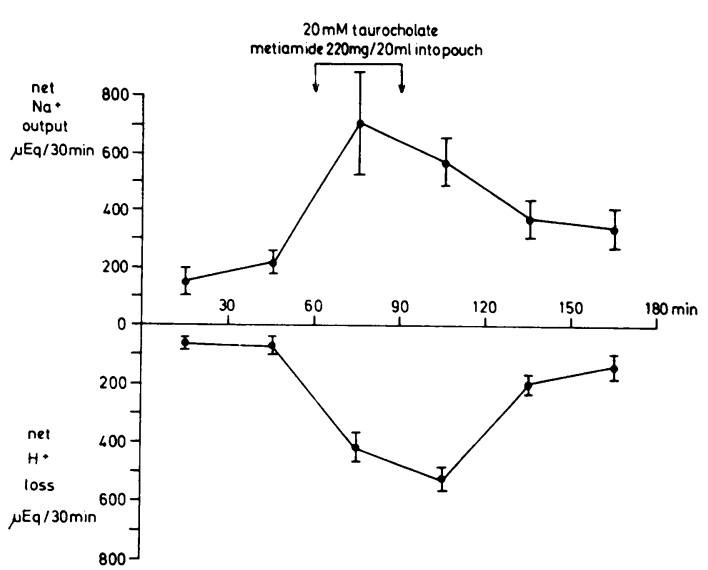

Fig. 8 Changes in the net $\mathrm{Na}^{+}$output and net $\mathrm{H}^{+}$loss after addition of metiamide $220 \mathrm{mg}$ to $20 \mathrm{ml}$ of taurocholate solution during period 3.

fluxes did not alter from control levels (table I). When the same dose of metiamide was added to $20 \mathrm{ml}$ of taurocholate solution (fig 8) there was still a significant increase in $\mathrm{H}^{+}$back diffusion during the period when metiamide was in the solution. However, the back diffusion of $\mathrm{H}^{+}$during this period was significantly less marked than that observed when the taurocholate solution was used without added metiamide (table I, P $<0.02$ ). For later periods there was no difference from the control taurocholate experiments. The net output $\mathrm{Na}^{+}$for all periods, including period 3, was not different from control taurocholate experiments.

Figure 9 shows the $\mathrm{Na}^{+}$and $\mathrm{H}^{+}$fluxes when

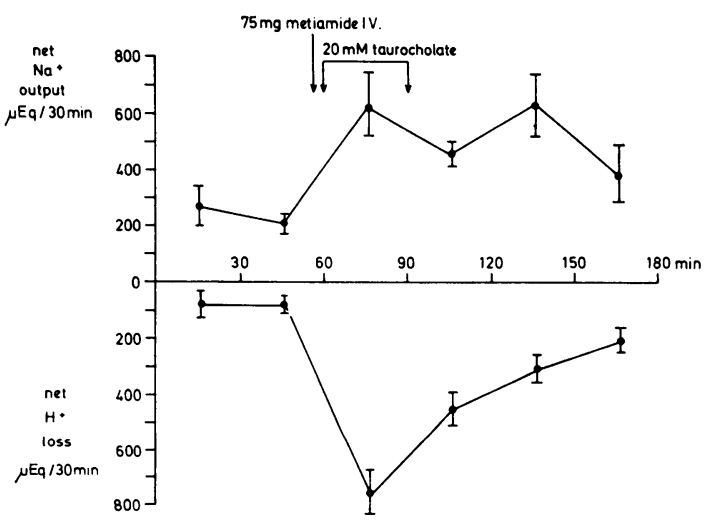

Fig. 9 Changes in the net $\mathrm{Na}^{+}$output and net $\mathrm{H}^{+}$loss diffusion after administration of $75 \mathrm{mg}$ metiamide intravenously before exposure of the pouch to taurocholate solution during period 3. 
$75 \mathrm{mg}$ metiamide was administered intravenously before the taurocholate solution was used in an attempt to modify the damaging effect by blockade of the histamine $\mathrm{H}_{2}$-receptors. No change in the degree of barrier damage is evident.

\section{Discussion}

The results presented indicate that $16-\mathrm{diMe}-\mathrm{PGE}_{2}$ when given into the pouch causes disruption of the gastric mucosal barrier with a moderate but highly significant back diffusion of $\mathrm{H}^{+}$and a large increase in the net movement of $\mathrm{Na}^{+}$into the pouch. The dosage used $(300 \mu \mathrm{g})$ was of the same order as the oral dose of $20 \mu \mathrm{g} / \mathrm{kg}$ employed by Robert and Magerlein (1972) to achieve greater than $50 \%$ inhibition of histamine-stimulated gastric secretion when the compound was given to Heidenhain pouch dogs. However, the two regimes may not be strictly comparable in view of the larger surface area of the stomach in the experiments of Robert and Magerlein, the dilution effect of gastrointestinal secretions, and the possibility that some of the dose empties from the stomach before $\mathbf{3 0}$ minutes have elapsed.

Robert and Magerlein (1972) have also shown that in the dog, intravenous injection of $0.5 \mu \mathrm{g} / \mathrm{kg}$ of 16-diMe-PGE 2 gives highly potent inhibition of histamine-stimulated gastric secretion. However, when we gave the compound intravenously in doses of $0.5 \mu \mathrm{g} / \mathrm{kg}$ we were unable to demonstrate a change in the ionic permeability of the mucosa. The higher dosage of $2 \mu \mathrm{g} / \mathrm{kg}$ intravenously was used in an attempt to demonstrate similar changes in ionic permeability to those produced by intrapouch administration. Significantly the $\mathrm{H}^{+}$and $\mathrm{Na}^{+}$ fluxes were not changed by this four-fold elevation of dosage. Nor did the intravenously administered 16-diMe-PGE 2 result in any change in the response of the mucosa to $20 \mathrm{mM}$ taurocholate solution. Thus while 16-diMe-PGE 2 causes profound inhibition when given orally or intravenously, its effects on the gastric mucosal barrier are seen only after local appl:cation.

It appears highly probable that the damaging effect of intragastric 16-diMe-PGE 2 reflects a specific biological action rather than the non-specific chemical effect of a fatty acid. It has been shown that short-chain fatty acids in concentrations of $100 \mathrm{mM}$ can increase mucosal permeability (Davenport, 1964) but in our experiments the molar concentration of 16-diMe-PGE 2 was approximately $40 \mu \mathrm{M}$. The analogue was initially dissolved in absolute alcohol $(2 \mathrm{mg} / \mathrm{ml})$ and aliquots of this stock solution were then added to the basal solution, resulting in an alcohol concentration in the test solution of $0.75 \% \mathrm{v} / \mathrm{v}$. As Davenport (1967) has shown, the minimum alcohol concentration required to effect mucosal damage was between 8.2 and $14 \% \mathrm{v} / \mathrm{v}$, so that damage to the barrier in the present experiments cannot be attributed to the alcohol vehicle.

It has been suggested that prostaglandin $E_{2}$ and its analogues inhibit gastric acid and pepsin secretion by a direct effect on the secretory cell (Karim et al, 1973) possibly by influencing the rate of cAMP production. However, in view of the failure of the analogue to influence the gastric mucosal barrier when given intravenously it appears unlikely that its damaging action on the gastric mucosal barrier is mediated by the same mechanism as that responsible for gastric secretory inhibition.

The findings that high doses of 16-diMe-PGE 2 may disrupt the gastric mucosal barrier must be considered when assessing the therapeutic potential of the agent. It is conceivable that some of the apparent reduction in gastric secretion reported after oral use of the analogue in animals and man might have resulted from $\mathrm{H}^{+}$loss due to back diffusion after damage to the mucosal barrier. However, the dosage used in our experiments was higher than the oral dose which investigators have found necessary to cause profound inhibition of acid output in man and marked inhibition has also been reported after intravenous injection (Karim et al, 1973; Nylander and Andersson, 1974). It is, however, within the range of dosage under consideration, particularly, as the concentration of an orally administered agent within the stomach will depend largely on the residual volume within that stomach and thus the mucosa may be exposed to a considerable range of concentrations.

Further study of the effect of 16-diMe-PGE ${ }_{2}$ on the gastric mucosal barrier will be of interest. Prostaglandin $\mathrm{E}_{2}$ is a hormone-like substance which may have a key role in the regulation of cellular metabolism, particularly with respect to secretory activity. In the present experiments the analogue of prostaglandin $\mathrm{E}_{2}$ has been shown to cause damage to the gastric mucosal barrier akin to that produced by a wide range of compounds used in much higher concentrations. In common with these compounds, the prostaglandin is lipid soluble and therefore easily crosses the cell membrane. It is not inconceivable that prostaglandin $E_{2}$ is implicated in the disruption of the mucosal barrier by the standard barrier breakers such as bile salts and aspirin. However, minor modifications to the prostaglandin molecule can result in major alterations in biological activity and it remains to be shown whether the barrierbreaking action of 16-diMe-PGE 2 is shared by the parent prostaglandin $\mathrm{E}_{2}$ and other related analogues.

When metiamide was introduced into the canine 
pouch there was no change in the ionic permeability. As it is a weak base and appears to act as a receptor blocker rather than exerting any direct effect on cellular metabolism this result was expected. Of greater interest was the study of the effect of metiamide in modifying the action of sodium taurocholate, a known barrier breaker.

That histamine plays some part in disruption of the gastric mucosal barrier has been suggested by the finding of increased histamine content of gastric venous blood after damage to the mucosa with $20 \mathrm{mM}$ salicylic acid (Johnson and Overholt, 1967). Histamine has been strongly implicated in the plasma protein loss and fluid production that accompany damage to the barrier (Davenport, 1966). If histamine $\mathrm{H}_{2}$-receptors rather than the $\mathrm{H}_{1}$-receptors were implicated in the changes in ionic permeability of the gastric mucosa after injury by taurocholate we could anticipate that a histamine $\mathbf{H}_{2}$-receptor antagonist would modify this change. As metiamide is a weak base with a pKa of $7 \cdot 1$ it would be in an ionized state in the acid environment of the test solution and therefore poorly absorbed into the mucosa of the pouch. Thus intravenous administration would be required to demonstrate this modifying effect. However, pretreatment of the mucosa with either local or intravenous metiamide did not appear to alter the damaging capacity of taurocholate.

It is of interest that in those experiments where metiamide was added to the pouch in association with taurocholate during period 3 there is a significant decrease in $\mathrm{H}^{+}$back diffusion for this period. However, the buffering capacity of metiamide is such that $220 \mathrm{mg}$ is capable of buffering approximately $55 \%$ of the $\mathrm{H}^{+}$present in the solution of pH 1.2. As the rate of $\mathbf{H}^{+}$back diffusion is related to the initial concentration (Black, Hole, and Rhodes, 1971) any buffering effect would be expected to decrease that rate. The increase in $\mathrm{Na}^{+}$output during period 3 and the $\mathrm{H}^{+}$back diffusion during the later periods were identical with those of the taurocholate controls. The decrease in back diffusion of $\mathrm{H}^{+}$during period 3 is therefore felt not to represent any protective effect by metiamide on the gastric mucosal barrier but rather a consequence of buffering free $\mathrm{H}^{+}$by metiamide, thus decreasing the concentration gradient down which back diffusion would occur. It is extremely unlikely that this mechanism could account for the changes in ionic flux observed after local instillation of microgram doses of the prostaglandin analogue, which, as an ester of an organic acid, would not be expected to act as a buffer. We thus conclude that we have been unable to demonstrate an effect of histamine $\mathrm{H}_{2}$-receptor blockade on the ionic fluxes after gastric mucosal barrier damage and feel it is unlikely that these receptors play a significant role in this process.

We wish to thank Mr Ian Ansell for his technical assistance, Mrs B. Beck for assistance with preparation of the manuscript, and Professor A. P. M. Forrest for his support. We thank Dr Andre Robert of Upjohn for the supply of the prostaglandin analogue and Dr A Flind of Smith, Kline and French for the supply of metiamide.

\section{References}

Black, R. B., Hole, D., and Rhodes, J. (1971). Bile damage to the gastric mucosal barrier: the influence of $\mathrm{pH}$ and bile acid concentration. Gastroenterology, 61, 178-184.

Carter, D. C., Forrest, J. A. H., Werner, M., Heading, R. C., Park, J. and Shearman, D. J. C. (1974). Effect of histamine $\mathrm{H}_{2}$-receptor blockade on vagally induced gastric secretion in man. Brit. Med. J., 3, 554-556.

Davenport, H. W. (1964). Gastric mucosal injury by fatty and acetylsalicylic acids. Gastroenterology, 46, 245-253.

Davenport, H. W. (1966). Fluid produced by the gastric mucosa during damage to acetic and salicylic acid. Gastroenterology, 50, 487-499.

Davenport, H. W. (1967). Ethanol damage to canine oxyntic glandular mucosa. Proc. Soc. Exp. Biol. Med., 126, 657-662.

Grossman, M. I., and Konturek, S. J. (1974). Inhibition of acid secretion in dog by metiamide-a histamine antagonist acting on $\mathrm{H}_{2}$ receptors. Gastroenterology, 66, 517-521.

Johnson, L. R., and Overholt, B. F. (1967). Release of histamine into gastric venous blood following injury by acetic or salicylic acid. Gastroenterology, 52, 505-509.

Karim, S. M. M., Carter, D. C., Bhana, D., and Ganesan, P. A. (1973). The effect of orally and intravenously administered prostaglandin 16 : 16 dimethyl- $E_{2}$ methyl ester on human gastric acid secretion. Prostaglandins, 4, 71-83.

Nylander, B., and Andersson, S. (1974). Gastric secretory inhibition induced by three methyl analogs of prostaglandin $E_{2}$ administered intragastrically to man. Scand. J. Gastroent., 9, $751-758$.

Robert, A., and Magerlein, B. J. (1973). 15 methyl PGE, and 16, 16 dimethyl $\mathrm{PGE}_{2}$ : potent inhibitors of gastric secretion. Advanc. Biosci., 9, 247-253.

Wada, T., and Ishizawa, M. (1970). Effects of prostaglandins on the function of gastric secretion. (In Japanese.) Jap. J. clin. Med., 28, 2465-2468. 